oscillatory, and, therefore, account must be taken of the pressures involved in producing changes of motion, in consequence of which the pressures differ from those which would exist at any instant if the motion were steady. These pressures, which I have called the " $d \phi / d t$ pressures," after the term which produces them in the hydrodynamical equation, are completely modified in their action when continuous motion is replaced by discontinuous motion, but their effect can only be discussed from general principles. Other points are the effect of the ship's forward motion in increasing the steadying action, and the influence of bilge-keels in modifying pitching and in improving the steering of ships; the two last effects are further simple consequences of the properties of discontinuous motion.

We have seen that the action of bilge-keels in steadying a ship is largely modified by the actions of the sides of the ship, and is much augmented when the keels are placed in a suitable p)sition; and it is interesting to notice how the exigencies of trade, while they have necessitated the removal of keels from the middle line of the ship to the sides, have brought about such a change in the form of the section as to render the new position by far the most effective. In the old pointed-bottomed ship, the central keel was the best, as it not only intercepted the currents flowing round the bottom in each swing from side to side, but also produced a difference of pressure on the two sides whose moment was always opposed to rolling. In the modern flat-bottomed ship of rectangular section a central keel would be unfavourably placed for this purpose, as not only would the water tend to flow in the same direction as that in which the ship is rolling, producing a dininished pressure on the keel, but the differences of pressure on the sides of the ships would have a moment tending to diminish the resistance to rolling. The favourable position now commonly assigned to the bilge-keel is calculated to render its addition to ships of the greatest value in increasing their steadiness

G. II. BRYAN.

\section{THE "ORTHOSTIGMAT" LENS.}

A SPECIMEN of the new series of lenses issued under the joint auspices of Messrs. Beck and Steinheil, has been tested and examined by us. The lens is of the rectilinear symmetrical type with two equal combinations, each consist. ing of three elements. It is by special construction of the surfaces of these components that the remarkable qualities claimed for. and undoubtedly possessed by, the new lens are attained. The great drawback to the best of the oid type lenses was the curvature of field, and it is only in recent years that the discovery of the new varieties of glass has made it pussible to correct this, and at the same time perfect the corrections for spherical aberration and astigmatism. The result of the process is that each component of the lens is made up of a positive meniscus, with a double convex lens cemented on one side of it and a double concave one on the other. The centre positive lens will consequently have a lower power than the two outer ones.

When it is understood that each of the twelve surfaces involved in the complete lens is worked with such accuracy, that an error of $\mathrm{r} / 40,000$ th of an inch is inadmissible, the increased price, compared with the old types of lenses, is amply accounted for in the superior product obtained.

We have tested the lens, which is of about $4 \frac{3}{4}$ inches solar focus, and are quite salisfied that it fulfils to a high degree of perfection the claims made for it by the makers. Although the lens is listed for $\frac{1}{4}$ plate, the circle of good definition is much larger, and with a stop of $f / 16$ excellent definition was obtained over the whole of a plate. The lens at its greatest rapidity works at $f / 6 \cdot 3$, and at this aperture the definition appears very perfect over an area $4 \frac{1}{4}$ inches square. The makers call attention to the special attempts they have made to eliminate astigmatism, and it is not until an oblique pencil falls considerably beyond the listed angle that any distortion shows itself. To make this clearer, let the image of the sun, moon, a star, or any distant object, be focussed at the centre of the plate, and then the camera so tilted that the image falls gradually away to the extreme corner. The slightest distortion can be at once recognised in this manner. With the lens in question no distortion was evident until the image was received at an angle of about 30 degrees from the axis, and for another Io degrees further the resulting astigmatism, although present, was much less than is present closer to the axis in a rectilinear of the ordinary type. So that for an angle of view of over $60^{\circ}$ the new lens is practically non. astigmatic at the large aperture $f / 6.3$ This will recommend it especially for all process and copying work, where critical definition and speed are primary necessities. A word should be said concerning the focussing with these new lenses. This adjustment must be critical, as an almost imperceptible dis. placement of the plate will suffice to throw it out of the focal plane sufficiently to destroy the definition, and so create false impressions of the capabilities of the optical system. For all such work, therefore, only perfectly rigid apparatus is permissible.

Another important qualification of the lens is its comparative freedom from chromatic aberration, in virtue of which it will be useful for work connected with colour photography, obviating the laborious and uncertain corrections which are necessary in such work with the ordinary lenses, whose chromatic aberrations are only suppressed for the blue and yellow. Critical tests of this correction have not been possible, but sufficient have been made to show that the outstanding error is small.

On account of their covering power, the smaller sizes will be found excellent for low-power microphotography. The new lenses are obtainable with foci varying from $3 \frac{1}{2} \mathrm{in}$. to $23 \frac{1}{2} \mathrm{in}$. covering plates from $3 \frac{1}{4}$ in. square to $28 \times 24$ inches.

\section{UNIVERSITY AND EDUCATIONAL INTELLIGENCE.}

OXFORD. - The Romanes Lecture will be delivered by Dr. James A. H. Murray on Friday, June 22, upon "The Evolution of English Lexicography."

Sir William Thiselton-Dyer, F.R.S., has been made a permanent elector to the Sherardian Professorship of Botany, in succession to the late Prof. Bartholomew Price.

The Statute instituting Diplomas in Geography has been approved by Convocation, and is to remain in force until October, 1904.

The extensive bequest to the University under Mr. Fortnum's will has made an enlargement of the Ashinolean Museum necessary. The cost is estimated at $1500 /$, and towards this sum Brasenose College has offered a contribution of $500 l$.

At Merton College there will be an election to a fellowship on October 6, after an examination in Animal Physiology and Animal Morphology. Candidates are requested to inform the Warden by September Io of their choice between these two subjects, and to submit. if they wish, original papers or memoirs.

At a meeting of the Oxford University Junior Scientific Club, held on Wednesday, June 6, Sir John Burdon Sanderson, F.R.S., gave an account of the method he has been lately employing for producing tetanus in muscle, by means of telephone currents produced by musical sounds, showing how the results bear on the vexed question of the inherent rhythmicality of muscle and nerve-cell. The lecture was illustrated by experiments.

At a meeting of the abnve club held on Friday, June 15, Mr. T. C. Porter, of Eton College, described the growth of the shadow of the Peak of Teneriffe, as witnessed from the summit of the mountain at sunrise and sunset, and its gradual eclipse by the shadow of the earth. He showed photographs taken at the time, and explained how by means of an ordinary watch and pair of opera glasses a rough value of the diameter of the earth might be deduced.

Mr. A. F. Walden, New College, made a preliminary communication to the club on the theory of labile hydrogen atoms.

CAMbridge. - The researches of Mr. J. C. McLennan on electrical conductivity in gases traversed by kathode rays, and of Mr. R. L. Wills, of St. John's College, on the magnetic properties of iron as influenced by temperature and the presence of other elements, have been approved by the Degree Committee as qualifying for the B.A. degree.

In the Natural Sciences Tripos, which is now the largest of the Honour Examinations, forty men and three women are placed in the first class of Part I. In Part II. fourteen men and no women obtain first-class honours.

At St. John's College the following awards in natural science were made on June I8. Foundation Scholars continued or elected: Lewton-Brain, May, Adams, Ticehurst, Fletcher, Browning, Wakely, Gregory, Williams, Harding, IIepworth, 